\title{
Eclipses: revelando a vida secreta das estrelas e da natureza humana
}

Eclipses: Revealing the secret life of stars and human nature

\author{
Daniel Brito de Freitas*10 \\ ${ }^{1}$ Universidade Federal do Ceará, Departamento de Física, Fortaleza, CE, Brasil.
}

Recebido em 07 de Agosto de 2019. Aceito em 11 de Agosto de 2019.

\begin{abstract}
O presente artigo é uma homenagem ao legado deixado pelo maior experimento astronômico do século XX. Os eclipses e suas multifaces são o alvo principal desse artigo. Veremos que os eclipses não somente revelam os segredos das estrelas, mas também aqueles da natureza humana. A inspiração e fascínio pelos eclipses nos tornaram capazes de prever o futuro e imaginar tais fenômenos em outros sistemas solares. Para mergulhar nesse mundo fascinante, iremos percorrer os caminhos que levaram uma espécie de primatas nômades, munidos de lascas de pedra e ossos, a criar maravilhosas máquinas que nos levaram a lugares jamais pensados. Nesse percurso, faremos uma reflexão sobre como cientistas e pensadores se empenharam em manter acessa a chama da liberdade e do livre pensamento. O artigo segue apresentando o pano de fundo histórico que culminou na comprovação da Teoria da Relatividade de Einstein no céu sobralense. Os dois tópicos seguintes apontam as questões abertas na astrofísica que são resultados da investigação de eclipses: o problema da coroa solar e a descoberta de exoplanetas através da técnica de trânsito planetário. For fim, um retrato geral sobre a onda de obscurantismo que questionam as leis da física e, em particular, os eclipses é apresentado.
\end{abstract}

Palavras-chave: Eclipse Solar, Relatividade Geral, Sobral, Albert Einstein.

The present paper is a tribute to the legacy left by the largest astronomical experiment of the twentieth century. Eclipses and their multifaces are the main target of this paper. We will see that eclipses not only reveal the secrets of the stars, but also those of human nature. Inspiration and fascination with eclipses have enabled us to predict the future and imagine such phenomena in other solar systems. To immerse ourselves in this fascinating world, we will walk the paths that led a kind of nomadic primate with splinters of stone and bone to create wonderful machines that took us to places never thought of. Along the way, we will reflect on how scientists and thinkers have endeavored to maintain the flame of freedom and free thought. The paper goes on to present the historical background that led to the proof of Einstein's Theory of Relativity in the Sobral's sky. The next two topics point to the open questions in astrophysics that are the result of eclipse research: the solar corona problem and the discovery of exoplanets through the planetary transit technique. Finally, a general picture of the wave of obscurantism that questions the laws of physics and, in particular, the eclipses is presented.

Keywords: Solar Eclipse, General Relativity, Sobral, Albert Einstein.

\section{A inspiração que precisamos}

Todos os corpos caem na presença de um campo gravitacional. A maçã que cai da macieira respeita a mesma lei física que mantém os planetas na órbita do Sol. O Sol detém mais de $95 \%$ da massa do sistema solar e seu campo gravitacional é muito intenso. Nem mesmo o gigante gasoso Júpiter pode colocar em risco a soberania do Sol. Essas observações são baseadas na mecânica newtoniana. Essa mecânica descreve com muita exatidão a maioria dos fenômenos na Terra. Ela mesma levou o homem à Lua. Sem perigo de generalidade, pode ser inferido que todos os humanos estão mais aptos a entender a física de Newton do que a de Einstein.

*Endereço de correspondência: danielbrito@fisica.ufc.br
Mas quem foi Einstein? E o que o tornou a celebridade científica mais pop do século XX? Crianças, jovens e adultos de qualquer parte do mundo diriam que isso se deve ao seu cabelo assanhado, à sua foto icônica com a língua para fora ou a sua emblemática equação $E=$ $m c^{2}$. Essas são marcas inseparáveis da popularidade de Einstein. É muito difícil pensar sobre o que passava na cabeça dele ao imaginar que o mundo descrito pela mecânica de Sir Isaac Newton trapaceia nossos sentidos em escalas astronômicas. Mesmo diante da dificuldade de entender a relatividade de Einstein e seus famosos experimentos mentais (p.ex., o paradoxo dos gêmeos) as pessoas conseguem formar opiniões sobre ele, seja pela inteligência singular ou mesmo quando pensam sobre tempo, espaço e buracos negros [1].

Einstein e seu legado científico e filosófico serão sempre fontes de inspiração para crianças e jovens de todo o 
mundo. Em particular, um dos feitos mais notáveis e mais complexos já produzidos por Einstein, a Teoria da Relatividade Geral, está mais próximo do Ceará e do Brasil do que imaginamos.

O eclipse solar de 1919 em Sobral tem um sabor histórico diferente e talvez sua extensão não seja totalmente entendida por moradores locais [2]. Talvez eles não tenham ideia da dimensão desse eclipse e o que ele trouxe para a história da humanidade, mas, certamente ficarão impressionados se descobrirem que esse feito está associado à figura de Albert Einstein. Em 1915, aos 36 anos de idade, Einstein publicou a Teoria que mudaria a história do pensamento humano para sempre e, em particular, a história de Sobral. Ele sabia, a partir da teoria de Newton, que a luz tem "peso" e pode cair na presença de um campo gravitacional (ver Figura 1). O que ele mostrou foi que a previsão newtoniana para campos gravitacionais fortes falhava. Em sua Teoria da Relatividade Geral, ele mostrou que essa falha é gritante e, para o campo gravitacional do Sol, a teoria geral previa que a deflexão da luz de uma estrela ao passar próximo do Sol era duas vezes maior do que a prevista por Newton $[3,4]$.

A comprovação dessa previsão colocou Einstein definitivamente entre as maiores mentes já produzidas pela humanidade, ao lado de Galileu e Newton. Esse foi o cenário de repercussão que Sobral mergulhou, um cenário semelhante ao que Galápagos foi para Darwin.

"A pergunta que minha mente formulou foi respondida pelo ensolarado [!] céu do Brasil"

A frase acima mencionada foi dita por Einstein em visita ao Brasil em 1925 e sintetiza sua capacidade que teve de imaginar a luz torcendo antes do experimento. Depois de 100 anos, Sobral, o Brasil e o mundo têm um compromisso de perpetuar esse legado. Os resultados científicos extraídos do eclipse que ocorreu em Sobral representam a ousadia da nossa espécie, a ousadia de uma mente. O presente artigo é uma tentativa de expandir a concepção científica e epistemológica desse fenômeno e mostrar que a dança entre o Sol e a Lua que termina em um abraço no céu sobralense é um evento que dá luz a outras importantes empreitadas científicas como veremos mais adiante. Mas antes, qual a raiz dessa ousadia?

\section{Os Sapiens adoram padrões}

Pensar requer recursos que vão além da sobrevivência da espécie. A evolução da nossa espécie até o nível de inteligência que propiciou a criação de métodos e ferramentas científicas que culminaram, em particular, na astrofísica, só foi possível através de um cérebro "desproporcional" ao resto do corpo. É claro que estamos sendo injustos com várias outras particularidades que ocorreram no passado do Cosmo como, por exemplo, a pequena vantagem da massa do próton em detrimento a do nêutron, levando ao surgimento do DNA e as mais diversas formas de vida na Terra. No entanto, vamos nos restringir ao momento que essa espécie "insignificante", conforme o Historiador Yuval Harari, se preocupou com os padrões a sua volta. O "poder cerebral" tornou os Sapiens limitados fisicamente e no combate corpo a corpo estavam constantemente em desvantagem. Como bem sintetizou Harari, "um chimpanzé não pode ganhar uma discussão com um Homo Sapiens, mas pode parti-lo ao meio como uma boneca de pano" [8].

Sapiens são apaixonados por padrões e regularidades, fatores esses que se tornaram essenciais para a sobrevivência da espécie. A independência cognitiva veio trazer o desenvolvimento de habilidades que estão fora do âmbito genético e da própria evolução biológica. Tais habilidades são resultado de várias tomadas de decisões que passaram na cabeça dos nossos ancestrais caçadores-coletores, como invadir um território inimigo ou migrar para outro local a procura de abrigo e comida. A cerca de 10 mil anos, os Sapiens decidiram focar seus esforços em domesticar animais e plantas, abandonando sua condição nômade e, por sua vez, reduzindo seu espaço de convívio
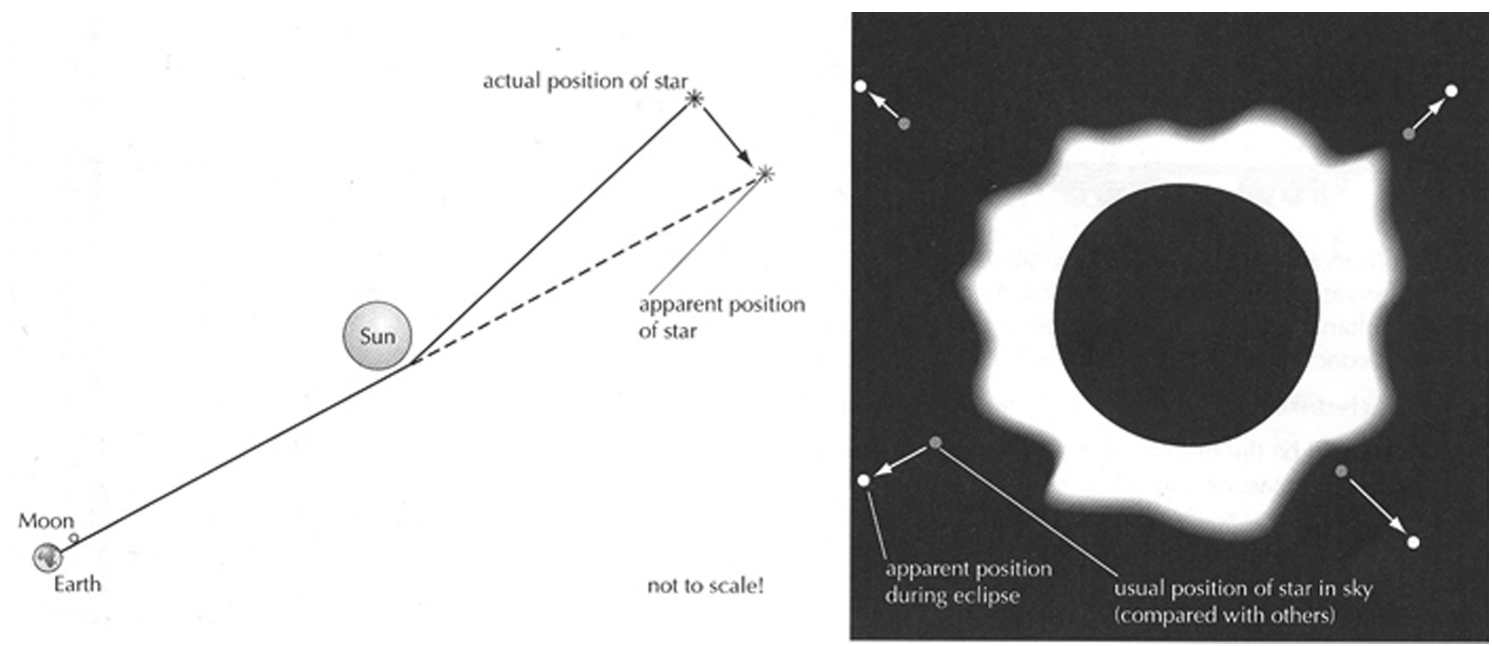

Figura 1: llustração esquemática do deslocamento sofrido pela luz de uma estrela nas imediações do Sol. Créditos: Arthur Eddington. 
e exploração [8]. Nesse momento, o papel da observação elevaria a espécie a um patamar sem precedentes: o poder da previsibilidade. A auto-domesticação, ou seja, o processo de viver em um espaço limitado onde pudesse explorar a terra e os animais, rendeu aos Sapiens a preocupação de que seu pequeno universo só poderia se manter viável sob a prerrogativa de um cuidado especial. É com isso que vem à tona a dependência sobre o comportamento previsível da natureza. Foi exatamente dessa forma, entendendo como a natureza se comporta, que chegamos ao consenso científico de que para entender o funcionamento do Cosmos devemos seguir um conjunto de regras iniciadas pelos nossos ancestrais e aperfeiçoadas por empenho de geração de pensadores como Galileu, Newton e Einstein [9]. Essa maneira de entender o momento certo do plantio e colheita foi ganhando corpo ao longo da história. As mensagens escritas no céu abriam espaço para novas interpretações e ajudavam nossos antepassados quando da chegada da chuva e do inverno. Saímos dos contos e fábulas que atribuíam ao humor e desejos dos deuses o curso da vida até o momento, já na era moderna, onde conseguimos equacionar a complexidade da natureza. Essa passagem só foi possível porque uma outra regra importante foi colocada em prática, a da questionar toda e qualquer autoridade, o Nillius in Verba que reside no coração do Método Científico. Veja Por Si Mesmo é o lema máximo do fazer científico.

Ainda sob o dogma da autoridade divina, nossos ancestrais viam certos fenômenos como o prelúdio do castigo e da ira dos deuses. A passagem de cometas e um eclipse solar total eram vistas como sinais de decadência, morte de reis e o fracasso nas guerras. É fácil para o homem moderno julgar que nossos ancestrais eram infantis em suas interpretações, mas até pouco tempo, não mais que meio milénio, nós acreditávamos que a Terra era imóvel e que o Sol girava em torno da Terra $[8,9]$.

Assim como Giordano Bruno, Galileu e Kepler, Newton questionou os dogmas existentes. Ele encontrou uma forma de revelar as entranhas da realidade, como um oráculo que tem acesso ao deus do tempo e do espaço [9].

\section{Sir Isaac Newton: o oráculo de Deus}

Maravilhados e indefesos aos fenômenos sem explicação, restava aos nossos antepassados se adaptaram aos temores e suplicar pela misericórdia dos deuses. Diante do mistério da natureza encontramos uma saída didaticamente justificável: se eu não posso explicar as coisas, coloco essa responsabilidade para algo fora desse mundo, imaginando que essa entidade tenha livre acesso ao desconhecido e que seja nosso intermediário. Como recompensa, criamos rituais que julgamos satisfazer os desejos inumanos dessa entidade divina, não necessariamente uma, mas várias como algumas civilizações politeístas acreditavam. Tentando entender como a natureza funcionava, o Homo Sapiens firmou um pacto que nos confinaria para sempre na ignorância, nos tornando escravos da própria criação.
A liberdade desse confinamento ao mundo divino teve sua dissociação com uma importante ajuda que Isaac Newton recebeu de Edmond Halley. Um particular cometa, o mesmo que outrora alimentou a imaginação de nossos ancestrais, que visitou o nosso céu inúmeras vezes, é o principal personagem dessa fantástica história que reúne o desejo de Halley de entender os cometas e a rebeldia da mente de Newton. Nessas várias visitas, o Sol vem implacavelmente dissolvendo a superfície desse cometa na forma de uma exuberante cauda, deixando escapar para sempre parte da história da formação do Sistema Solar [9].

A amizade de Newton e Halley consolidou a teoria da gravitação universal e pôs por terra a frágil explicação sobrenatural. Newton já tinha em sua mente poderosas informações sobre como os planetas orbitam em torno do Sol. A lei dos períodos de Johannes Kepler foi fundamental para entender a força misteriosa que coordena a dança dos planetas. Em um dia de agosto de 1684, um encontro mudou a história da ciência para sempre. Halley foi ao encontro de Newton com a esperança de encontrar respostas sobre uma possível lei matemática que descrevesse a força gravitacional. Para o espanto de Halley, Newton já tinha em mãos uma teoria que explicava o puxão gravitacional entre os planetas e o Sol. Essa lei dependia do inverso do quadrado da distância. Halley se encarregou de levar à Sociedade Real em Cambridge o trabalho de Newton para publicação. Mas, sem verbas para impressão, a Sociedade não aceitou o trabalho. Sem os esforços de Halley, a Revolução Científica que estava sendo sinalizada pela obra de Newton teria um atraso ou mesmo nunca teria sido publicada. Esse trabalho foi mais tarde chamado de Principia. Um tratado de ciência contendo os princípios básicos sobre espaço, tempo e movimento [10].

Halley estudou vários dados astronômicos de cometas e descobriu que um deles cruzava o céu a cada 78 anos. Usando o Principia, ele previu a próxima passagem desse cometa e, com isso, mostrou como a ciência era capaz de prever fenômenos. Infelizmente, quando o cometa cruzou o céu de Londres em 1758 Halley já havia falecido. Hoje esse cometa é conhecido como Cometa Halley. No entanto, Halley foi muito além dessa profecia. Para confirmar o poder profético das leis de Newton, ele pensou em uma empreitada mais audaciosa: a previsão de um eclipse solar total. Seus cálculos previam que na manhã do dia 3 de maio de 1715 a cidade de Londres iria escurecer. Sua confiança era tamanha que ele espalhou pela cidade cartazes alertando sobre o eclipse. Em suas palavras citou: "Poucos segundos antes que o Sol fosse totalmente escondido, foi descoberto ao redor da Lua um anel luminoso de cerca de $3 / 4$ de uma polegada, ou talvez uma décima parte do diâmetro da Lua, em extensão. Era de uma brancura pálida, ou ao invés disso, era de uma cor de pérola, parecendo para mim um pouco tingido com as cores da íris, e parecia ser concêntrico com a Lua" [11]. Halley narrava o esplendor da Coroa Solar. 
Aproximadamente 100 anos depois, Leibniz levou o poder de previsibilidade das leis de Newton às últimas consequências, afirmando que bastava ter em mãos as condições iniciais do Universo para descrever com perfeição todo o seu passado e prever o futuro com precisão infinita. É verdade que as equações que saem do Principia fornecem com exatidão o momento e posição que ocorrerá um eclipse. Esse feito, da mecânica clássica de Newton, confirmou a ideia que Einstein tinha em sua mente: o bloqueio da passagem da luz do Sol em um eclipse solar total revelando uma realidade escondida pela ofuscante luz do Sol. Esse mérito veio antes da Teoria da Relatividade Geral apoiada na concepção passiva de uma natureza submetida às leis determinísticas da mecânica newtoniana.

Essas leis seguem os ritmos do determinismo. Não somente previsões de eclipses e passagem de cometas são os interesses da física newtoniana, mas sobretudo o desejo de demonstrar que os Sapiens tem o domínio sobre o tempo e o espaço e, portanto, a natureza poderia ser desvendada pela matemática. Ainda na época de Einstein, a física newtoniana era vista desta forma como detentora de uma validade ilimitada. No entanto, Henri Poincarè mostrou que essa verdade dependia das condições iniciais, aquilo que foi chamado de "sensibilidade às condições iniciais", um problema que nasce quando tentamos entender a dinâmica de dois corpos influenciado por um terceiro [12]. Mais tarde, a literatura se encarregou de chamá-lo de Princípio do Terceiro Excluído. Esse comentário pode parecer fora de contexto, mas ele é muito importante para entender todo esse cenário. Em suma, calcular a trajetória de uma pedra que cai em direção ao centro da Terra (problema de dois corpos isolados) é mais fácil do que estimar o comportamento de um sistema de três corpos, por exemplo, o sistema Sol-Terra-Lua, como se configuram os eclipses.

Essa sutileza levantada por Poincarè não afetou o pensamento de Einstein e da maioria dos físicos da época. $\mathrm{Na}$ verdade, para um evento previsto em uma escala de tempo muito menor que milhares de anos, essa observação pode parecer apenas um capricho. Desde o Principia até a relatividade geral e a física quântica, a concepção de tempo não permite qualquer distinção entre o passado e o futuro e, portanto, os eventos no Universo não são perturbados pelo Clinamen ${ }^{1}$ de Epicuro. Existe mais em um eclipse do que nossa vã ciência newtoniana acredita $[12]$.

\section{O sútil senhor Einstein}

Nas palavras de Richard Feynman a lei da Gravitação Universal de Newton foi "a maior generalização concebida pela mente humana" [13]. Assim, como Feynman, não estamos interessados na mente humana, mas na elegância

\footnotetext{
1 Uma hipótese levantada por Epicuro onde eventuais momentos imprevisíveis perturbam imperceptivelmente o andamento de um momento como, por exemplo, um eclipse.
}

e simplicidade que a lei demonstra. A lei do inverso do quadrado da distância, como é comumente resumida, foi essencial para matematizar a lei dos períodos formulada por Kepler. A lei da gravidade é expressa matematicamente como: $F=G \frac{m_{1} m_{2}}{r_{12}^{2}}$, onde $G$ é a famosa constante da gravitação universal, as massas dos corpos (Terra e Lua, por exemplo) são denotadas pelo produto no numerador da fração e, logo abaixo, o termo de distância que consolida a equação $[9,13]$.

No entanto, a equação acima não é suficiente para prever um eclipse sendo necessário incluir o tempo na equação. Isso é possível com a ajuda de outra equação newtoniana: $F=m \cdot a$. Essa equação dispensa comentários, seu conceito é utilizado em diferentes situações: do lançamento de um foguete à uma partida de futebol. Ela já está presente em nosso DNA, mesmo que alguns "Sapiens" a refutem em nome de uma paranoia esquizofrênica de que somos vítimas de um complô internacional, liderado pela NASA, nos colocando em um cenário semelhante ao filme Show de Truman [14].

Matematicamente, a terceira lei de Kepler nasce dessas equações e expressa tempo e espaço de tal modo que uma combinação específica entre elas gera o mesmo valor, independente da escolha do planeta que gira em torno do Sol. Resumidamente, $\frac{P^{2}}{r^{3}}=K$. O tempo $P$ nos dá acesso ao oráculo que tudo vê pelos olhos da terceira lei de Kepler. Da mesma forma, $r$ situa o encontro no espaço marcado pelo relógio que mede o tempo em ciclos periódicos de comprimento $P$. Daquelas equações estimamos que $K$ depende do inverso da soma das massas. Isso parece ferir o argumento de Kepler por assumi-la como uma constante [15]. Como a massa do Sol é muito maior do que a massa de qualquer planeta, o argumento é verdadeiro pelo simples fato de que a soma das massas é reduzida à massa do Sol. Por fim, a gravidade consolida as lacunas deixadas pelo modelo de Kepler e que outrora serviram de base para astrônomos e lideres religiosos na sua época atacarem o heliocentrismo. Newton colocou por terra a frágil crença de que a Terra era o centro do Universo. A previsão de eclipses está para além do desejo de Einstein em confirmar sua teoria, ela representa os esforços de gigantes para emancipar e libertar nossas mentes das amarras do dogma religioso.

O movimento do pensamento científico não é linear e uma ideia como a de Newton pode vestir a mesma máscara do dogma. Einstein aparece nesse cenário com a sutil tarefa de ser o próximo revolucionário, aquele traz de dentro do oceano da ignorância e da anestésica condição da validação temporal uma nova verdade científica. Para ultrapassar essa fronteira, Einstein vai recorrer a um eclipse solar total. Assim como o movimento científico, a trama histórica não é linear, mas, como sabemos o final da história, vários acidentes trarão a cidade de Sobral para perto dos holofotes [4].

Todos devem concordar que Einstein era um cientista de mão cheia. No entanto, não foi sua capacidade cognitiva de resolver equações complicadas e realizar Gedanke- 
nexperiment (experimentos imaginários em alemão) que o levaram ao posto de popstar mundial, mas sua capacidade de convencer os cientistas da época que apostar no sucesso da Relatividade Geral levaria seus nomes para as páginas dos livros de história. Não seria exagero afirmar que Einstein era uma "lobista" da ciência. Seu poder de persuasão convenceu astrônomos como Erwin Freundlich, assistente no Observatório de Berlim, o astrônomo real Frank Dyson e o cientista britânico Arthur Eddington, considerado na época o mais importante e influente astrônomo na Europa. Eddington saiu em campo para defender as ideias de um alemão de origem judaica em detrimento ao maior símbolo da ciência britânica, uma contradição em tempos de guerra.

Como já vimos anteriormente, as leis de física newtoniana são excelentes para prever acontecimentos dessa ordem e ela daria para Einstein uma data e localização precisas sobre um eclipse solar. No entanto, a comprovação da teoria está subordinada a outro importante elemento: a previsão poderia nos dar uma data tão longínqua que seria necessário hibernar a teoria. Einstein já tinha em mãos o valor teórico de 0,8 " ( 0,8 segundos de arco) da deflexão da luz segundo a teoria de Newton $[1,2]$. Esse cálculo, elaborado pelo matemático alemão Johann Georg Von Soldner, era aproximadamente a metade do valor previsto pela Relatividade Geral. Essa discrepância tem origem na ideia de Einstein em considerar que, no caso de um eclipse solar total, uma teoria do campo gravitacional fraco seria diferente se considerasse a versão forte que a teoria newtoniana não contemplava.

O eclipse que cruzaria a América do Sul e a África Central no dia 29 de maio de 1919 ocorreria muito próximo ao aglomerado de estrelas conhecido como as Híades. Esse é um aglomerado estelar aberto e está localizado na constelação de Touro. Como se trata de um aglomerado jovem, com pouco mais de 650 milhões de anos, as estrelas são brilhantes e, dentre elas, a brilhante Aldebaran se destaca como a estrela alfa da constelação.

Um eclipse solar total revela-se como um "método" eficaz para desvendar o estranho mundo escondido pelos caprichos da gravidade. Sem dúvida, as atenções estavam voltadas para o desvio que a luz sofre ao passar próximo do campo gravitacional do Sol, mas a silhueta deixada pelo disco de luz em volta da Lua eclipsante revela outros "subprodutos", tais como, a coroa solar "quente" e a ejeção de massa coronal. Os eclipses são fontes poderosas para entender o mecanismo interno do Sol, a interação Terra-Sol e até mesmo o clima do nosso sistema $[16,17]$.

\section{A verdade não revelada do Sol}

Antes de iniciar esta seção, eu gostaria de argumentar sobre que impressão esse artigo daria se fosse lido por um filósofo. Para os cientistas, uma descrição fenomenológica resguardada de um aparato matemática causaria uma boa impressão. Mas o texto poderia estar subnutrido do ponto de vista filosófico.
Vários cientistas assumem uma postura kantiana consciente ou inconscientemente no sentido de acreditar que a realidade é orientada pelas ideias e teorias. Em última análise, a realidade é aquilo que não estamos vendo ou ainda carece de predicados. Ela está escondida por trás de uma densa cortina de fumaça, onde uma nova teoria deve ter fôlego suficiente para soprar essa fumaça, jogando-a para longe. A física clássica é kantiana por funcionar sobre a premissa do Princípio da Causalidade, ou seja, uma física que preza leis determinísticas [18]. O princípio da causalidade legitima a busca por leis naturais, mesmo que sua existência não passe apenas de um desejo alimentado pelo cientista. Assim, a ding an sich (a coisa em si em alemão) estaria fora de nosso alcance e a ciência se tornaria um andarilho no mundo das imperfeições, no mundo das aparências [19].

Indianos, babilônicos e chineses já tinham observado as protuberâncias da atmosfera solar em eclipses, mas foram os eclipses solares mais recentes que elucidaram esse fenômeno. Os primeiros eclipses, dentre eles o eclipse de 1919 em Sobral, confirmaram as saliências na superfície e, para além dela, foram capazes de anunciar atividades secretas do Sol jamais vistas. Isso é possível por que existe um encaixe perfeito do disco lunar e a borda do Sol [20]. Quando Mercúrio corta o disco solar, fenômeno conhecido como trânsito de Mercúrio, não é possível inferir a existência dessas atividades. Quando a Lua cobre inteiramente o disco solar na fase conhecida como "anel de diamante" é possível verificar que a atmosfera solar se estende por milhões de quilômetros. A coroa solar é sem dúvida a região mais enigmática da atmosfera. Em síntese, na coroa a temperatura é centenas de vezes maior do que a da base da fotosfera, a esfera de luz que limita a borda visível do Sol. Os eclipses anteciparam os estudos acerca da coroa solar em mais de meio século, mas somente na década de 1940 a astrofísica conseguiu dar uma espiada mais de perto [19].

Em muitos artigos de divulgação científica encontramos metáforas para explicar esse enigma. O mais usado é o da panela que ferve repousando sobre um bloco de gelo. Outro, mais didático, seria imaginar que estamos na frente de uma fogueira e na medida que nos afastamos dela a temperatura do ar em nossa volta aumenta ao invés de diminuir. Para o leitor atento, as analogias dizem que tal fenômeno fere o enunciado de Clausius da segunda lei da termodinâmica. Esse princípio afirma que é impossível o calor fluir de um corpo mais frio (a fotosfera) para um corpo mais quente (a coroa) por processos espontâneos. Do ponto de vista termodinâmico a coroa solar é um excelente condutor térmico, isso significa dizer que as partículas do gás contido na atmosfera absorvem pouco calor e, portanto, a temperatura do gás sofre uma pequena variação na medida que nos afastamos da superfície do Sol [21].

Mais recentemente, em 2013, a NASA enviou a sonda espacial IRIS (Interface Region Imaging Spectrograph) para estudar a região de interface entre a fotosfera e a at- 
mosfera solar. No entanto, a sonda tinha outro propósito em jogo: assegurar que a física térmica que estudamos nas escolas não foi violada. Essa atitude não é desprovida de um interesse filosófico $[18,19]$. Mesmo que a reação da comunidade científica seja de assegurar o conhecimento vigente, testado e aprovado em diferentes circunstâncias, existe um princípio mais fundamental por trás. Esse princípio fundamental é kantiano e se nutrir da ideia que a ciência é baseada em conhecimentos sintéticos a priori. Isso porque não podemos tirar analiticamente (observando apenas o objeto) que a coroa é superaquecida, precisamos agir sobre o objeto e por isso mandamos sondas espaciais [21]. Essa é a forma como a ciência avança: alimentar o objeto de predicados extraídos da experiência. Ou seja, intuitivamente os cientistas sabiam que os pressupostos da física não iriam ser abandonados e que escolas não deixariam de ensinar termodinâmica. Basta encontrar uma sutileza lógica de inserir o novo predicado sem que ele não negue a própria ciência.

\section{Ao encontro de novos mundos}

Hoje não precisamos esperar um eclipse para estudar a atmosfera solar e todos seus mecanismos que ditam o comportamento do magnetismo do Sol. Eclipses artificiais criados pela sonda espacial SoHO (Solar and Heliospheric Observatory) fornecem informações preciosas sobre a matéria ejetada, onde com o auxílio da lei de Faraday da Indução, inferimos sobre o motor que mantem o Sol magneticamente ativo. Não somente de termodinâmica a atmosfera sobrevive, mas de explosão de plasmas de partículas carregadas que dançam no espaço seguindo a sinfonia tocada pelas linhas do campo magnético [21].

Máquinas no espaço turbinam o conhecimento humano onde jamais poderíamos chegar. Essa aventura no espaço é guiada pelos Sapiens, mas são as máquinas que chegam mais perto dessa realidade, algumas a ponto de se despedir da "vida artificial" com um mergulho suicida, como aquele que ocorreu com a sonda Cassini-Huygens em 2017. Talvez a mais espetacular aventura seja a busca por planetas fora do sistema solar usando uma nova vertente dos eclipses: o trânsito planetário $[16,17,20]$.

Em 29 de maio de 1919 ocorreu em Sobral o famoso eclipse solar que deu a Teoria de Relatividade de Einstein a primeira comprovação observacional [1]. Eclipses não são dádivas apenas no nosso sistema, eles são encontrados em qualquer parte do Universo. O eclipse solar total é visto pelo observador quando existe um alinhamento perfeito entre a Terra, a Lua e o Sol. Sem dúvida, esse é o mais sublime de todos os eclipses, mas existem outras versões tão importantes quanto essa. Nossa posição no sistema solar permite visualizar outros dois eclipses: os de Mercúrio e Vênus. Para esses eclipses os astrônomos batizaram de "trânsito" [17]. Dada a proximidade desses dois planetas, uma simples chapa de soldador é suficiente para proteger nos olhos dos raios nocivos do Sol e realçar o pequeno ponto que corta o disco solar. Uma questão que vem à tona é: se é possível observar a silhueta de Mercúrio e Vênus, seria também possível para planetas fora do nosso sistema? Basicamente, uma empreitada dessa magnitude requer indícios de que planetas são abundantes na Galáxia.

Essa ideia nos remete aos tempos de Giordano Bruno, um frade dominicano que foi levado à fogueira da Santa Inquisição porque acreditava na ideia de Deus diferente das Escrituras Sagradas. Um Deus limitado pela periferia do mundo aristotélico. Inspirado pelo livro De Rerum $\mathrm{Na}$ tura de poeta romano Lucrécio, Giordano imaginou um universo repleto de mundos como o nosso, onde pessoas e animais existiam [17]. Essa foi sua fonte de inspiração para declarar que o Deus do cristianismo era tão pequeno quanto o intelecto de Papas e sacerdotes. A inquisição reduziu Giordano a cinza, mas não conseguiu apagar suas ideias. Se hoje a comunidade de astrônomos e astrofísicos procuram por mundos habitáveis é porque alguém corajoso como Giordano resistiu ao autoritarismo com a própria vida. Ela pagou com a vida para que sua ideia permanecesse viva e outros como ele tivessem a coragem de não recuar quando estivessem diante do tribunal da opressão [9].

Logo após o Natal de 2006, cientistas e engenheiros europeus lançaram o primeiro satélite em busca desses eclipses em outros sistemas estelares. A missão CoRoT (Convection, Rotation et Transits planétaires) tinha como fonte de inspiração investigar du coeur des étolies aux planètes habitables (do coração das estrelas aos planetas habitáveis) [22]. Desde o primeiro planeta descoberto orbitando uma estrela como o Sol até hoje, quase 4000 mundos "giordanianos" foram encontrados, alguns muito maiores que Júpiter e outros tão pequenos quanto a Terra. Os Estados Unidos enviaram em 2009 o satélite espacial Kepler com a missão de superar os números do CoRoT. A missão Kepler, também aposentada, foi responsável por quase $70 \%$ de todos os exoplanetas detectados, independente da técnica utilizada. Ambas missões tem como base a queda da luz emitida pela estrela quando o exoplaneta cortar o disco estelar. Isso significa que uma boa parcela de planetas que não respeitam essa condição será invisível para a missão.

Esses planetas estão a anos-luz de distância e mesmo com toda engenharia sofisticada presente nos telescópios espaciais é impossível ver a silhueta desses planetas com os mesmos detalhes dos trânsitos de Mercúrio e Vênus. Mas isso não é problema para os astrofísicos. Foi mencionado na seção anterior que a terceira lei de Kepler deduzida a partir da gravitação universal e as leis da mecânica de Newton nos fornece a relação entre o período da órbita do planeta e a distância entre ele e a estrela. No entanto, a lei dos períodos de Kepler não é suficiente para registrar a passagem de um exoplaneta longínquo. É preciso recorrer a outra lei da física: a radiação térmica de um corpo negro. Inicialmente, vamos considerar que todas as estrelas que olhamos em 
uma noite estrelada são corpos negros perfeitos. O nosso Sol também pode ser incluído nessa categoria.

Dos compêndios de física, encontramos a definição de corpo negro como um corpo hipotético que absorve toda a radiação eletromagnética que nele incide. Como um exemplo, se o papel que você imprimisse esse artigo fosse um corpo negro perfeito, seria impossível ler o seu conteúdo. Por outro lado, todos os corpos emitem radiação, simplesmente porque tudo que existe no Universo tem uma temperatura resultada da agitação térmica de átomos e moléculas. Assim, um corpo negro também emite radiação térmica e essa emissão pode ser entendida usando a famosa lei de Planck da radiação. Dela é suficiente saber que a temperatura da fonte (em particular, uma estrela) pode ser estimada através da lei de Wien, matematicamente expressa pela relação $T=\frac{0,003 \mathrm{~m} \cdot K}{\lambda_{\max }}$, onde $\lambda_{\max }$ é o comprimento de onda onde a intensidade da radiação de corpo negro é máxima. Além dessa informação, a lei de Stefan-Boltmann completa o arcabouço teórico necessário para entender como a passagem de um planeta afeta o fluxo de radiação de uma estrela. Essa lei nos diz que a intensidade $I$ de toda radiação emitida por uma estrela dependente exclusivamente da quarta potência na temperatura, ou seja, $I=\sigma T^{4}$, onde $\sigma$ é conhecida como constante de Boltzmann. Essas são as ferramentas científicas para entender os eclipses em longas distâncias.

A Figura 2 descreve o diagrama de fase do trânsito do exoplaneta CoRoT-11b. O eixo das ordenadas se refere à intensidade do fluxo de energia em Watts normalizado ao valor do fluxo sem a presença do trânsito, por isso que o gráfico começa em 1,000. Sabemos que a intensidade da radiação é a razão entre a potência emitida $P$ e a área $A$ do disco estelar. Com isso, o fluxo de energia ou potência é $P=I \cdot A$. Se não ocorrer trânsito esse fluxo deve permanecer praticamente constante, salvo as flutuações da atividade magnética que ocorrem na fotosfera, mas que não alteram a amplitude do fluxo de energia em mais do que uma fração de $0,1 \%$. O leitor

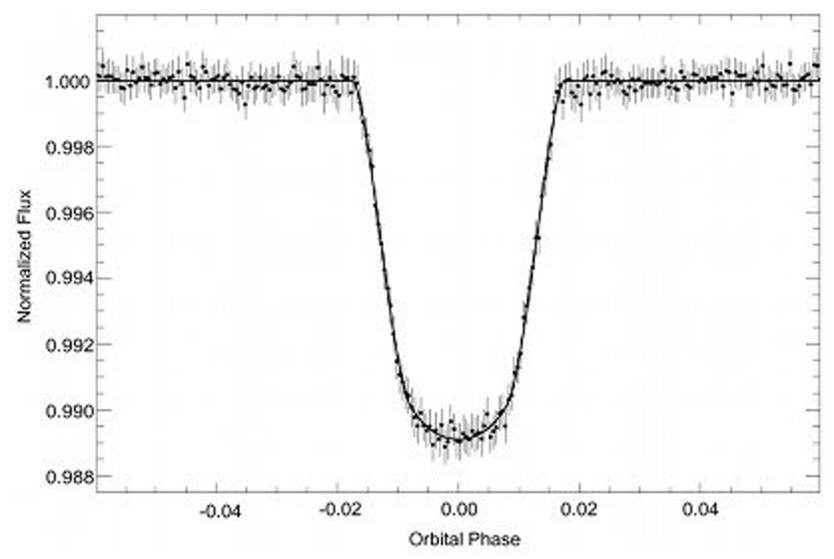

Figura 2: Diagrama de fase do trânsito do exoplaneta CoRoT11b. Créditos: CoRoT Mission [19]. pode se perguntar: o que é essa "amplitude do fluxo de energia"? Basicamente, ela é "receita" para se determinar o tamanho do exoplaneta. Quando o exoplaneta cortar o disco estelar, a área que emitida da radiação será reduzida pela "área escura" do planeta, ou seja, $A_{\text {trânsito }(t)}=$ $A-A_{\text {planeta }(p)}$. Deste modo, o fluxo de energia durante o trânsito sofrerá uma redução deduzida da expressão $P_{t}=$ $I \cdot A_{t}$. Depois de um pouco de algebrismo, concluímos que $\frac{A_{t}}{A}=\frac{P-P_{t}}{P}$, onde o segundo membro da expressão é a famigerada amplitude. Considerando que estrela e exoplaneta são discos perfeitos, a expressão anterior nos fornece a razão entre os raios do exoplaneta e da estrela:

$$
\frac{R_{p}}{R_{*}}=\sqrt{\frac{P-P_{t}}{P}}
$$

(equação2).

No caso do CoRoT-11b, a amplitude é 0,01 e, portanto, o raio do exoplaneta é apenas $10 \%$ do raio da estrela. Para encontrar o raio do exoplaneta é necessário encontrar o raio da estrela. A tarefa é relativamente fácil, bastando medir a intensidade de radiação no referencial da Terra. As estrelas emitem radiação radialmente em todas as direções e sua intensidade é controlada pela lei do inverso do quadrado da distância. Essa distância $d$ pode ser medida pelo método conhecido como paralaxe trigonométrica ${ }^{2}$ Como a potência independe da distância, ela deve ser a mesma em qualquer ponto. Ao contrário, a intensidade de radiação medida na Terra $I_{T}$, depende da distância. Compilando essas informações, chegamos à conclusão de que $R_{*}=\sqrt{\frac{I_{T}}{I}} d$.

Em um eclipse solar total, a Lua encobre totalmente o fluxo de energia do Sol. Nesse caso, a área do trânsito $A_{t}$ é ZERO e, portanto, concluímos que a Lua tem o mesmo raio do Sol! Na verdade, visto por um observador na Terra, isso é possível porque a Lua e Sol tem aproximadamente a mesma distância angular de 0,5 graus. Por isso que essa combinação não é possível em um "eclipse exoplanetário", nunca encontraríamos uma condição tão perfeita a ponto da profundidade do trânsito ser máxima, ou seja, $P-$ $P_{T}=1$ (veja a Figura 2 para concluir essa afirmação).

A estrela KIC 8462852, amplamente conhecida como estrela de Tabby, um apelido dado em homenagem a astrofísica Tabetha Boyajian, abriga um exótico objeto (veja que não foi usado o nome exoplaneta) na qual obscurece o disco estelar em mais de $20 \%$. A pouco foi citado que CoRoT-11b reduz o fluxo da estrela em $1 \%$. Usando a mesmo percurso matemático, o objeto de Tabby teria aproximadamente a metade do raio de KIC 8462852 (KIC é um código que significa Kepler Input Catalog ${ }^{3}$ ). Como um exemplo, um alienígena, apontando seu telescópio

\footnotetext{
2 O telescópio espacial Hipparcos da Agência Espacial Europeia mediu com altíssima precisão a paralaxe de quase 120 mil estrelas na vizinhança solar. Recomendo ao leitor dar uma pequena pausa e estudar um pouco mais sobre o que é e como é medida a paralaxe. Uma boa referência é o link: http://astro.if.ufrgs.br/dist/

3 Ver o site para maiores detalhes: https://archive.stsci.edu/kepler/kic.html
} 
para o nosso sistema iria concluir, usando as mesmas equações acima, que Júpiter reduz o fluxo do Sol em $1 \%$ e, portanto, $10 \%$ do raio solar. Várias teorias foram sugeridas para explicar a anomalia da estrela Tabby. Algumas fogem do escopo científico, como foi o caso de especularem que se tratava de uma Megaestrutura alienígena [23].

A ciência tem sempre o cuidado em levantar hipótese quando se deparam com o "mistério". Prudência é a postura do cientista. Devaneios são guiados à luz do método científico. Por fim, situações como essa são testes importantes não só para falsear uma teoria (no sentido Popperiano), mas também para verificar como a sociedade se sente mais atraída por ideias mirabolantes do que com a cautela da ciência. Cientistas não aparecerão na televisão dizendo: "encontramos a primeira cidade alienígena, o primeiro aperto de mão interestelar será no próximo mês". No entanto, recentemente uma onda de obscurantismo tem ganhado força mundo a fora. A situação é muito mais grave que a declaração do hipotético cientista na televisão. A nova onda propaga fake news de um conluio premeditado entre a NASA e os cientistas de todo o mundo para esconder a verdade sobre a ida do homem à Lua, sobre as vacinas e os fósseis dos dinossauros, dentre outras alucinações [24]. No contexto do presente artigo, o terraplanismo é o modelo que quer substituir a Terra Esférica por uma chapa redonda coberta por uma tampa de acrílico. Seus adoradores enxergam sinais ocultos na natureza e tal estado de paranoia os levam a pregar o evangelho do obscurantismo.

\section{Eclipse na era do Obscurantismo}

Circulou pelas mídias sociais uma imagem que simboliza o eclipse lunar sob a ótica dos terraplanistas. A imagem publicada no Tweet do icónico astrofísico norte-americano Neil deGrasse Tyson mostra uma sombra da terra-plana cruzando o disco lunar. A figura era acompanhada pela seguinte mensagem: "A Lunar Eclipse flat-Earther's have never seen" ("Um Eclipse Lunar que os terraplanistas jamais viram"). Em um eclipse lunar o nosso planeta se interpõe entre a Lua e o Sol bloqueando a luz solar e projetando uma sombra que denota a superfície esférica da Terra. Como a Terra gira em torno de seu eixo, não existe a menor chance em que o "perfil" dela pudesse projetar a imagem tão sonhada pelos terraplanistas e imaginada por Tyson [25]. Mas nunca duvide da capacidade insana dos "Sapiens", assim como, os "curandeiros quânticos" acham que a força do pensamento pode mudar a estrutura molecular da água, os terraplanistas podem com a força do pensamento concluir que o eclipse lunar é um complô da NASA projetando no céu uma imagem manipulada pelo Photoshop. No entanto, a imaginação conspiratória deles não tem o cuidado de pensar que essa difícil tarefa requer um ajuste de imagens para diferentes observadores em diferentes partes da Terra. Essa empreitada fantasiosa certamente tomaria boa parte do orçamento da NASA.
Por mais que pareça desnecessário, não custa nada mencionar algumas evidências convincentes de que a Terra é redonda e gira em torno de seu eixo. Não é recente que as evidências da esfericidade da Terra são concebidas. Aristóteles notou que durante os eclipses lunares, a sombra sobre a superfície da Lua é redonda. Ele conclui que essa sombra é a da Terra, conotando uma ótima pista acerca de sua forma esférica. Outro fato se deve à rotação da Terra que produz uma sombraoval à medida que o eclipse evolui, provando não apenas que a Terra é redonda, mas esférica. Ao retornar de uma viagem ao Egito, Aristóteles observou que haviam estrelas vistas no Egito que não são vistas nas regiões do norte (mundo grego), concluindo novamente que este fenômeno só é possível se a Terra for esférica. A única observação equivocada de Aristóteles foi considerar que a Terra não deveria ser muito grande já que tais mudanças foram observadas em pequenas distâncias.

Em meados do século XIX outra experiência demonstra com razoável facilidade a rotação da Terra: o pêndulo de Foucault. O experimento é tão simples que pode ser feito em casa. Esse experimento deixa claro que o sentido do giro do pêndulo com relação ao plano projetado no chão é diferente de um hemisfério para outro, mostrando que, ao girar, temos a impressão que o pêndulo foi empurrado para o lado. A força de Coriolis é responsável por explicar esse fenômeno, da mesma forma que explica o sentido da rotação dos furações e ciclones [26]. Se a Terra fosse plana e imóvel, atletas de arco e flecha em Olimpíadas não precisavam "dar um desconto" ao atirar no alvo. Esse "desconto" permite que o arqueiro atinja o alvo apontando o arco mais à esquerda ou à direita dependendo do hemisfério onde os jogos olímpicos estão ocorrendo. Em suma, além de declararem que a Terra é plana, os terraplanistas devem vir a público declarar que furações e ciclones também são uma ilusão. Podem demonstrar isso fazendo um "cruzeiro rumo a borda de um furação categoria F5". Se é para assumir essa teoria que vá até as últimas consequências.

O obscurantismo tem vários tentáculos, o terraplanismo é apenas um deles. Ele está se tornando pouco a pouco uma alternativa ao conhecimento científico. Isso é muito grave e não se trata mais de uma fase de histeria coletiva. Para quem acompanha o cenário mundial, é possível apontar para algumas pistas sobre sua origem. Talvez a mais evidente sejam as bolhas sociais criadas em aplicativos como WhatsApp e Facebook. O "echo chambers" do sociólogo polonês Zygmunt Bauman parece ser a forma mais didática para explicar a sustentação de uma sociedade paralela nutrida por soluções mágicas. $\mathrm{O}$ eco da própria voz é a bússola que guia o indivíduo que buscam nas redes socias "salas de espelhos" com objetivo de refletir única e exclusivamente a sua imagem.

Na contramão dessa prática insana temos a ciência e a filosofia. Elas educam para a responsabilidade intelectual e social. Uma responsabilidade que passa pelo entendimento dos pares através de uma postura livre 
das amarras herméticas que o dogma cego promove. $\mathrm{O}$ retrocesso civilizatório é o resultado de uma sociedade em crise existencial que nega os fatos consumados pela história e pelo método científico e filosófico no lugar de teorias conspiratórias cultivadas em solo insalubre tomado por pragas. O que a Realidade teria a dizer dessa estranha e dolorosa realidade que tenta injustamente difamá-la? Certamente, tais adoradores da decadência intelectual não são presos à superfície da Terra pela força da gravidade, mas pelos já velados deuses do passado. Querem transgredir as leis da física pelo puro desejo pessoal apoiado por um sentimento de vingança e inveja daqueles que pela ciência colhem os melhores frutos que eles mesmos consomem. Esse mundo fictício tem uma grande desvantagem em relação ao mundo dos sonhos. Esse último ao menos é resultado de estímulos retidos no subconsciente, enquanto o primeiro é a negação da realidade. Talvez, em seus sonhos, os terraplanistas enxerguem um mundo mais real do que aquele que frequentam quando "acordados".

A árvore do conhecimento está sendo ameaçada por uma onda de obscurantismo com a mesma carapuça dos inquisidores medievais. Temos o dever como espécie de preservar essa árvore. Queremos ser lembrados como é lembrada a geração de Giordano Bruno. A comemoração dos cem anos da comprovação da Teoria da Relatividade Geral de Einstein em Sobral é um alerta sobre a nossa responsabilidade histórica.

\section{Agradecimentos}

Daniel Brito de Freitas agradece ao $\mathrm{CNPq}$ pelo apoio financeiro à pesquisa (CNPq-PQ2 grant No. 311578/20187). De Freitas também agradece à professora Nara Jaqueline Avelar Brito pela revisão do texto e correções ortográficas. As atividades de pesquisa do STELLAR TEAM da Universidade Federal do Ceará são mantidas por financiamento contínuo do CNPq através de bolsas de iniciação científica.

\section{Referências}

[1] A. Pais, "Sutil é o Senhor ...": A Vida e a Ciência de Albert Einstein (Nova Fronteira, São Paulo, 1982).

[2] A. Sponsel, British Journal of History of Science 35, 439 (2002).

[3] S. Singh, Big Bang (Record, São Paulo, 2014).

[4] A.A. Passos Videira, Física na Escola 6, 1 (2005).

[5] D. Kennefick, Physics Today 62, 37 (2009).

[6] F. Dyson, A. Eddington e C. Davidson, Philosophical Transactions of the Royal Society of London. Series A, Containing Papers of a Mathematical or Physical Character 220, 291 (1920).

[7] H. Morize, Revista de Sciencias 3, 65 (1920).

[8] Y.N. Harari, Sapiens: Uma Breve História da Humanidade (L\&PM, São Paulo, 2015).
[9] S. Weinberg, Para Explicar o Mundo: a Descoberta da Ciência Moderna (Companhia das Letras, Rio de Janeiro, 2015).

[10] R.S. Westfall, A Vida de Isaac Newton (Nova Fronteira, São Paulo, 1995).

[11] S.A. Mitchel, Eclipses of the Sun (Columbia University Press, New York, 1951).

[12] I. Prigogine, O Fim das Certeza: Tempo, Caos e as Leis da Natureza (Editora Unesp, São Paulo, 2011).

[13] R. Feynman, Física em 12 Lições (Ediouro, Rio de Janeiro, 2006).

[14] P. Roura e J. Calbó, Physics Education 40, 455 (2005).

[15] H.M. Nussenzveig, Curso de Física Básica Volume 1 (Blucher, São Paulo, 2004).

[16] M. Olivier, T. Encrenaz, F. Roques, F. Selsis e F. Casoli, Planetary Systems: Detection, Formation and Habitability of Extrasolar Planets (Springer, Berlin, 2008).

[17] M. Mayor e P. Frei, New Worlds in the Cosmos - The Discovery of Exoplanets (Cambridge University Press, Cambridge, 2003).

[18] N. Bohr, Philosophy of Science 4, 289 (1937).

[19] I. Kant. Crítica da Razão Pura (Vozes, Petrópolis; Editora Universidade São Francisco, Bragança Paulista, 2013), $2^{\mathrm{a}} \mathrm{ed}$.

[20] J.W. Mason (Ed.), Exoplanets - Detection, Formation, Properties, Habitability (Springer \& Praxis, Chichester, 2008).

[21] B. Carrol e D. Ostlie, An Introduction to Modern Astrophysics (Addison-Wesley, Boston, 1996).

[22] http://www.esa.int/Our_Activities/Space Science/COROT, acessado em jul. 2019.

[23] T.S. Boyajian, D.M. LaCourse, S.A. Rappaport, D. Fabrycky, D.A. Fischer, D. Gandolfi, G.M. Kennedy, H. Korhonen, M.C. Liu, A. Moor et al., MNRAS 457, 3988 (2016).

[24] W. Carpenter, One Hundred Proofs that the Earth Is Not a Globe (William Carpenter, Baltimore, 1885).

[25] N. de Grasse Tyson, Origens (Planeta, São Paulo, 2015).

[26] K.R. Symon, Mecânica (Campos, Rio de Janeiro, 1982). 